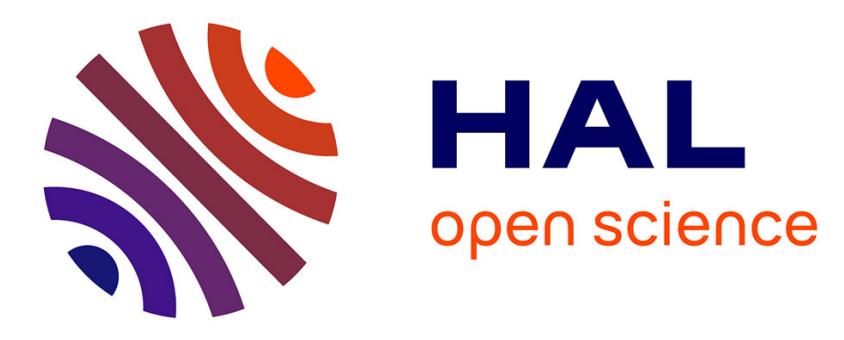

\title{
A novel mutation in the transmembrane 6 domain of GABBR2 leads to a Rett-like phenotype
}

Marie-Laure Vuillaume, Mederic Jeanne, Li Xue, Sophie Blesson, Anne-Sophie

Denomme-Pichon, Servane Alirol, Celine Brulard, Estelle Colin, Bertrand Isidor, Brigitte Gilbert-Dussardier, et al.

\section{To cite this version:}

Marie-Laure Vuillaume, Mederic Jeanne, Li Xue, Sophie Blesson, Anne-Sophie Denomme-Pichon, et al. A novel mutation in the transmembrane 6 domain of GABBR2 leads to a Rett-like phenotype. Annals of Neurology, 2018, 83 (2), pp.437-439. 10.1002/ana.25155 . hal-01730199

HAL Id: hal-01730199

https://hal-univ-rennes1.archives-ouvertes.fr/hal-01730199

Submitted on 13 Dec 2018

HAL is a multi-disciplinary open access archive for the deposit and dissemination of scientific research documents, whether they are published or not. The documents may come from teaching and research institutions in France or abroad, or from public or private research centers.
L'archive ouverte pluridisciplinaire HAL, est destinée au dépôt et à la diffusion de documents scientifiques de niveau recherche, publiés ou non, émanant des établissements d'enseignement et de recherche français ou étrangers, des laboratoires publics ou privés. 
A novel mutation in the TM6 domain of GABBR2 leads to a Rett-like phenotype

Vuillaume $\mathrm{ML}^{1,2}$, Jeanne $\mathrm{M}^{1,2}$, Xue $\mathrm{L}^{3}$, Blesson $\mathrm{S}^{1}$, Denommé-Pichon $\mathrm{AS}^{4,5}$, Alirol $\mathrm{S}^{2}$, Brulard $C^{2,6}$, Colin $E^{4,5}$, Isidor $B^{7,8}$, Gilbert-Dussardier $B^{9,10}$, Odent $S^{11,12}$, Parent $P^{13}$, Donnart $A^{14}$, Redon $\mathrm{R}^{14}$, Bézieau $\mathrm{S}^{7,15}$, Rondard $\mathrm{P}^{3}$, Laumonnier $\mathrm{F}^{1,2}$, Toutain $\mathrm{A}^{1,2}$

1 Service de Génétique, Centre Hospitalier Universitaire, Tours, France

2 UMR INSERM 930, Faculté de Médecine, Université François-Rabelais, Tours, France

3 Institut de Génomique Fonctionnelle (IGF), CNRS UMR5203 - INSERM U1191- Université de Montpellier, Montpellier, France

4 Service de Génétique, Centre Hospitalier Universitaire, Angers, France

5 UMR INSERM 1083 - CNRS 6015, Faculté de Médecine, Université d'Angers, Angers, France

6 Plateforme Biologie Moléculaire des Cancers, Centre Hospitalier Universitaire, Tours, France

7 Service de Génétique, Centre Hospitalier Universitaire, Nantes, France

8 INSERM, UMR-S 1238, Université de Nantes, Nantes, France

9 Service de Génétique, Centre Hospitalier Universitaire, Poitiers, France

10 EA 3808, Université de Poitiers

11 Service de Génétique Clinique, Centre Hospitalier Universitaire, Rennes, France

12 CNRS UMR 6290 IGDR, Faculté de médecine, Université de Rennes 1, Rennes

13 Génétique médicale, Centre Hospitalier Universitaire, Brest, France

14 INSERM, CNRS, Université de Nantes, Centre Hospitalier Universitaire, I'Institut du thorax, Nantes, France

15 CRCINA, INSERM, Université d'Angers, Université de Nantes, Nantes, France.

Corresponding author: $\operatorname{Pr}$ Annick Toutain, Service de Génétique, Centre Hospitalier Universitaire, 2 Boulevard Tonnellé, 37044 Tours cedex 9, France. Tel.: +33247478850; Fax: +33247478653; Email: annick.toutain@univ-tours.fr

Running head: A novel GABBR2 mutation in the TM6 domain

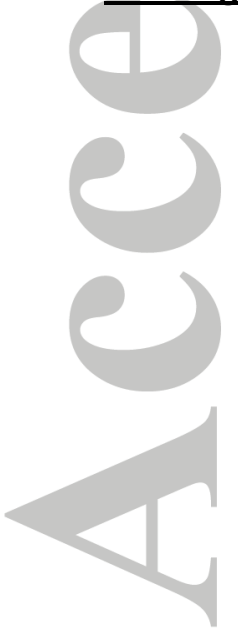


Dear Editor,

We read with great interest the recent article published by Yoo et al. ${ }^{1}$ reporting four additional RETT-like (RTT) patients with the recurring A567T GABBR2 mutation². More interestingly, they showed, with in vitro and in vivo functional studies, that the severity of the phenotype caused by GABBR2 mutations was directly linked to their impact on GABA signaling activity, this latter being more reduced with the two missense mutations, $\mathrm{S695I}$ and $1705 \mathrm{~N}$ associated with epileptic encephalopathy $(\mathrm{EE})^{1,3}$. They hypothesized that variants position in different transmembrane (TM) domains of GABBR2, TM6 for S695I and I705N, and TM3 for A567T, could determine the phenotypic expression. This hypothesis was recently reinforced with the report of a novel GABBR2 mutation also in TM6 and associated with infantile epileptic spasms ${ }^{4}$.

We present a novel de novo heterozygous GABBR2 mutation, A707T (Fig 1 A), identified by Whole Exome Sequencing also located in TM6 of GABBR2 (Fig 1B) but associated with a RTT phenotype. The carrier, a 12 year-old girl, had profound intellectual disability, hand stereotypies, sleep and breathing disturbances but no history of seizures. This mutation, predicted pathogenic by in silico analyses, lies in a region crucial for GPCR activation and positive allosteric modulation ${ }^{5}$. To assess its impact on GABA signaling activity, we coexpressed the two GABA ${ }_{B}$ subunits with the chimeric G-protein Gaqig in HEK-293 cells and measured the accumulation of inositol phosphate (IP-1) induced by the ligand GABA. We showed that the signaling activity of our A707T mutant is weakly induced by the agonist compared to that of the wild-type (Fig 1C), and this without altering GABBR2 cell surface expression (Fig 1D). The same results were observed with the A567T and I705N mutants (Fig 1C). Moreover, the four mutants tested have a basal activity stronger than that of the wildtype which might explain why the mutated receptor cannot be stimulated efficiently by 
GABA (Fig 1C,1E). This basal activity is reversed by the competitive antagonist CGP54626, except for the mutant $\mathrm{S695I}$ which is already fully active in the absence of GABA and do not respond to GABA (Fig 1C, E) in accordance with Yoo et al. data ${ }^{1}$. To conclude, our results show that GABBR2 mutations located within TM6 can also be associated with a Rett-like phenotype. The novel mutation described here, A707T, also exerts a deleterious effect on GABAB receptor activity. This deleterious effect could result from a constitutive activity of the mutated $G A B A_{B}$ receptor highlighting a novel putative pathogenic mechanism for GABBR2 variants.

\section{Acknowledgement}

This work was supported by grants from the French Ministry of Health and Health Regional Agency from Poitou-Charentes (HUGODIMS, 2013, RC14_0107). The funder has no role in study design, data collection, analysis, interpretation of the data, writing of the report and the decision to submit the paper for publication. We thank Dr. Xavier Rovira (University of Vic, Spain) for the structural model of the human GABAB2 7TM. The inositol-phosphate experiments have been performed using the ARPEGE (Pharmacology Screening-Interactome) platform facility at the Institut de Génomique Fonctionnelle (Montpellier, France).

\section{Author Contributions}

MLV, MJ, LX, PR, FL and AT contributed to the conception and design of the study. MLV, MJ, $\mathrm{LX}, \mathrm{SB}, \mathrm{ASD}, \mathrm{SA}, \mathrm{CB}, \mathrm{AD}, \mathrm{RR}, \mathrm{SB}, \mathrm{PR}, \mathrm{FL}$ and $\mathrm{AT}$ contributed to the acquisition and analysis of data. All authors contributed equally to drafting the text and preparing the figures.

\section{Potential Conflicts of Interest}

Nothing to report. 


\section{$\underline{\text { References }}$}

1. Yoo Y, Jung J, Lee YN, et al. GABBR2 mutations determine phenotype in rett syndrome and epileptic encephalopathy. Ann Neurol 2017;82:466-478

2. Lopes F, Barbosa M, Ameur A, et al. Identification of novel genetic causes of Rett syndrome-like phenotypes. J Med Genet 2016;53:190-199

3. EuroEPINOMICS-RES Consortium, Epilepsy Phenome/Genome Project, Epi4K Consortium. De novo mutations in synaptic transmission genes including DNM1 cause epileptic encephalopathies. Am J Hum Genet 2014;95:360-370

4. Hamdan FF, Myers CT, Cossette P, et al. High Rate of Recurrent De Novo Mutations in Developmental and Epileptic Encephalopathies. Am J Hum Genet 2017;101:664-685

5. Dupuis DS, Relkovic $D$, Lhuillier $L$, et al. Point mutations in the transmembrane region of GABAB2 facilitate activation by the positive modulator $N, N^{\prime}$-dicyclopentyl-2-methylsulfanyl 5-nitro-pyrimidine-4,6-diamine (GS39783) in the absence of the GABAB1 subunit. Mol Pharmacol 2006;70:2027-2036

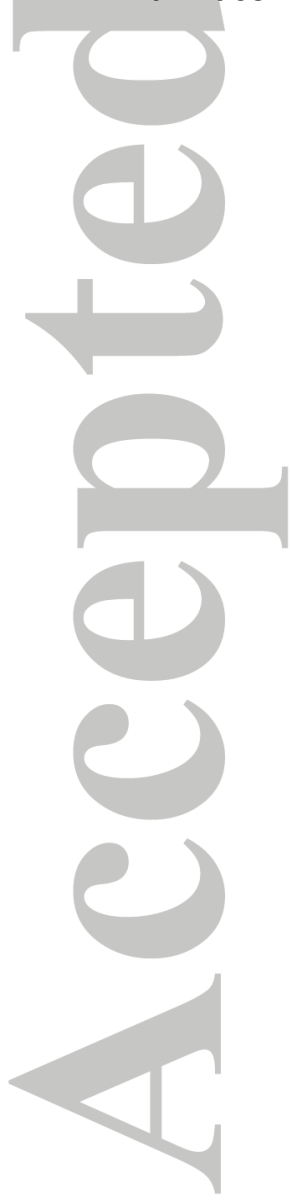




\section{Figure legend}

Figure 1: Identification and functional analysis of the A707T mutation

A) Sanger sequencing electrophoregrams showing the GABBR2 heterozygous missense mutation c.2119G>A, p.(Ala707Thr) in the proband and wild-type sequences in her parents and amino-acid alignments showing high conservation of the residue 707 across multiple species. TM: Transmembrane domain.

B-E) Functional analysis of the $\mathrm{GABA}_{B}$ receptor mutants. B) Structural model of the human $\mathrm{GABA}_{\mathrm{B} 2}$ heptahelical transmembrane domain (7TM) with the mutated residues in RTT and EE patients indicated in Corey-Pauling-Koltun representation. All the amino acid residues affected by the human mutations are in transmembrane (TM) domains 3 and 6. C) Inositolphosphate accumulation mediated by the wild-type and mutant Flag-tagged $\mathrm{GABA}_{\mathrm{B} 2}$ coexpressed with the wild-type $\mathrm{GABA}_{\mathrm{B} 1 \mathrm{a}}$ and the chimeric $\mathrm{G}$ protein subunit $\mathrm{G}_{\alpha q_{i 9}}$ (a $\mathrm{G} \alpha q$ protein in which the last nine C-terminal residues have been replaced by those from $\mathrm{Gai}_{2}$ ) which facilitates the coupling of Gi-coupled receptors to the phospholipase $\mathrm{C}$ signaling pathway (Monnier et al, 2011). Data are means \pm SEM of at least three independent experiments. D) Cell surface levels of the Flag-tagged $\mathrm{GABA}_{\mathrm{B} 2}$ mutants when co-expressed

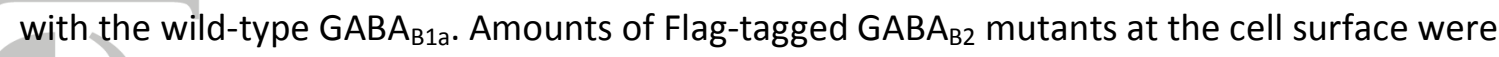
quantified by ELISA in intact (i.e. non-permeabilized) cells using the Flag epitope at the extracellular $\mathrm{N}$-terminus of the $\mathrm{GABA}_{\mathrm{B} 2}$ subunit. Data are expressed as means $\pm \mathrm{SEM}$ of triplicates from a typical experiment repeated at least three times. E) Inositol-phosphate accumulation mediated by the wild-type and mutant Flag-tagged $\mathrm{GABA}_{\mathrm{B} 2}$ co-expressed with the wild-type $G A B A_{B 1 a}$ and $G \alpha q_{i g}$, as in panel $B$. The $G A B A_{B}$ receptor wild-type and $G A B A_{B}$ mutants were incubated with $100 \mu \mathrm{M}$ GABA, $10 \mu \mathrm{M}$ CGP54626 or both. Data are means \pm SEM of at least three independent experiments. 
Monnier C., Tu H., Bourrier E., et al. (2011) Transactivation between two 7-TM domains:

implication heterodimeric GABAB receptor activation. EMBO J. 30, 32-42.

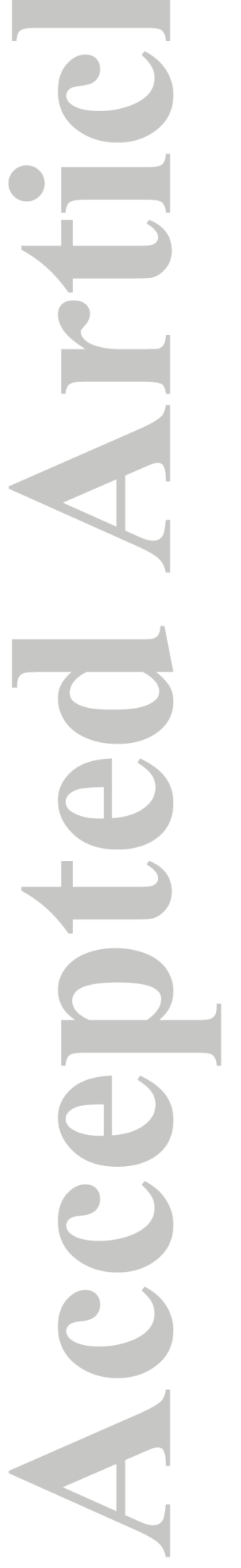


A

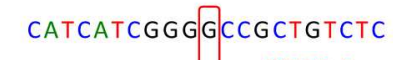

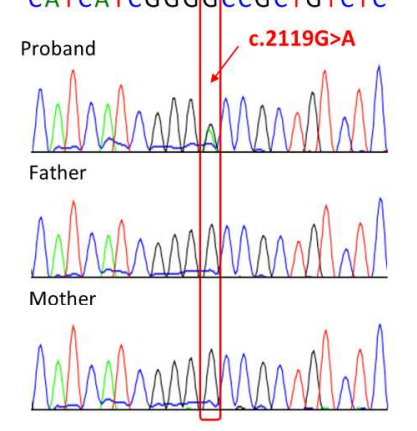

Human Chimpanzee Macaque

Rat

Dog

Cat

Cow

Opossom

Ornithoryncus

Chicken

Xenopus

Tetraodon

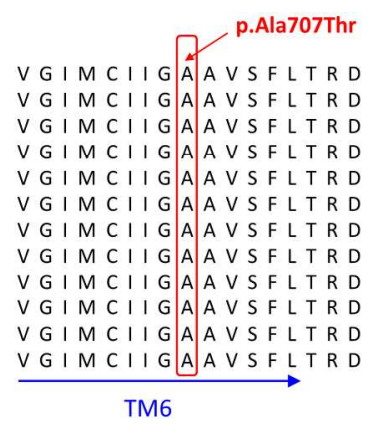

C $\quad \mathrm{hGABA}_{\mathrm{B1a}}+\mathrm{hGABA}_{\mathrm{B2}}+\mathrm{Gqi}_{9}$
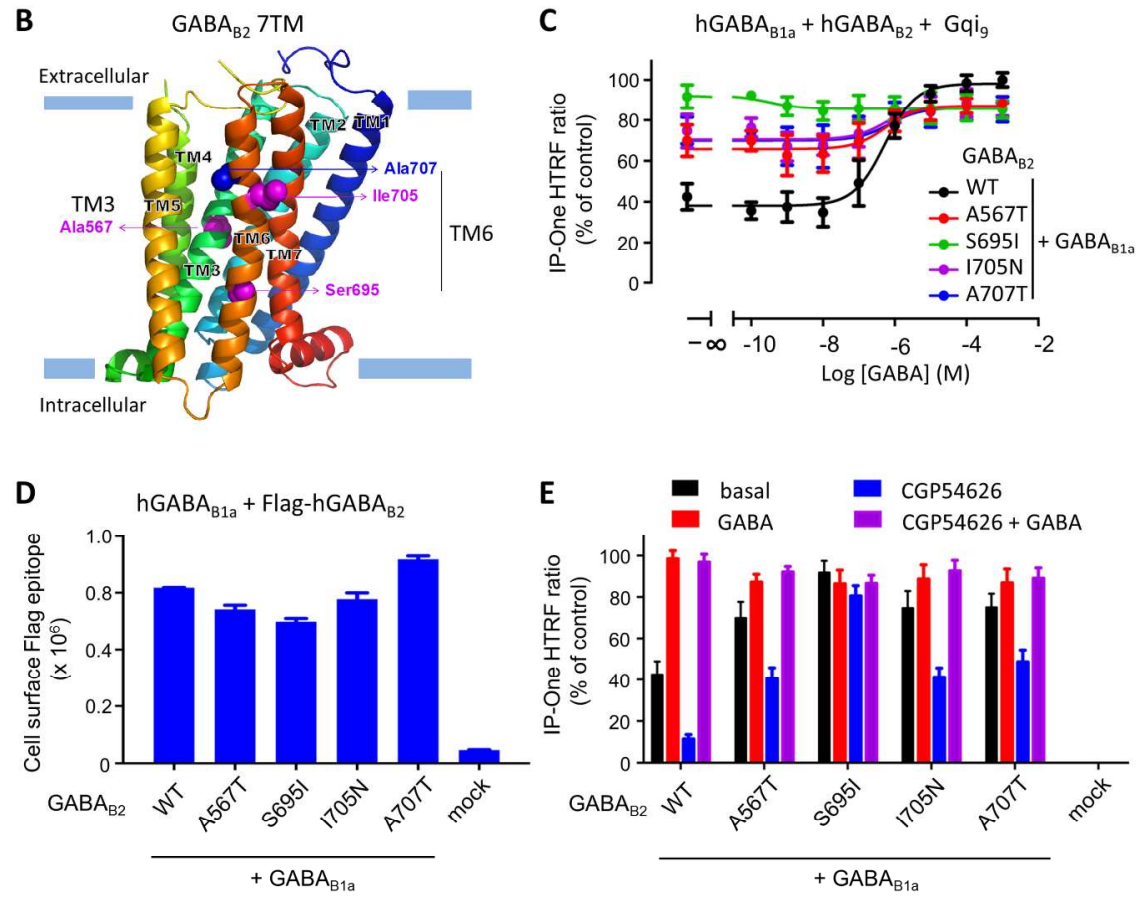

Figure 1: Identification and functional analysis of the A707T mutation

A) Sanger sequencing electrophoregrams showing the GABBR2 heterozygous missense mutation c. 2119G >A, p. (Ala707Thr) in the proband and wild-type sequences in her parents and amino-acid alignments showing high conservation of the residue 707 across multiple species. TM: Transmembrane domain.

B-E) Functional analysis of the GABAB receptor mutants. B) Structural model of the human GABAB2 heptahelical transmembrane domain (7TM) with the mutated residues in RTT and EE patients indicated in Corey-Pauling-Koltun representation. All the amino acid residues affected by the human mutations are in $\checkmark$ transmembrane (TM) domains 3 and 6. C) Inositol-phosphate accumulation mediated by the wild-type and mutant Flag-tagged GABAB2 co-expressed with the wild-type GABAB1a and the chimeric G protein subunit Gaqi9 (a Gaq protein in which the last nine C-terminal residues have been replaced by those from Gai2) which facilitates the coupling of Gi-coupled receptors to the phospholipase $\mathrm{C}$ signaling pathway (Monnier et al, 2011). Data are means \pm SEM of at least three independent experiments. D) Cell surface levels of the 
Flag-tagged GABAB2 mutants when co-expressed with the wild-type GABAB1a. Amounts of Flag-tagged GABAB2 mutants at the cell surface were quantified by ELISA in intact (i.e. non-permeabilized) cells using the Flag epitope at the extracellular N-terminus of the GABAB2 subunit. Data are expressed as means \pm

SEM of triplicates from a typical experiment repeated at least three times. E) Inositol-phosphate accumulation mediated by the wild-type and mutant Flag-tagged GABAB2 co-expressed with the wild-type GABAB1a and Gaqi9, as in panel B. The GABAB receptor wild-type and GABAB mutants were incubated with $100 \mu \mathrm{M}$ GABA, $10 \mu \mathrm{M}$ CGP54626 or both. Data are means \pm SEM of at least three independent experiments.

Monnier C., Tu H., Bourrier E., et al. (2011) Transactivation between two 7-TM domains: implication heterodimeric GABAB receptor activation. EMBO J. 30, 32-42.

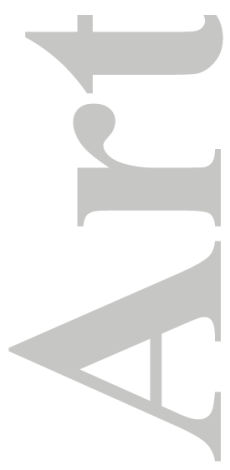

$254 \times 338 \mathrm{~mm}(300 \times 300$ DPI $)$

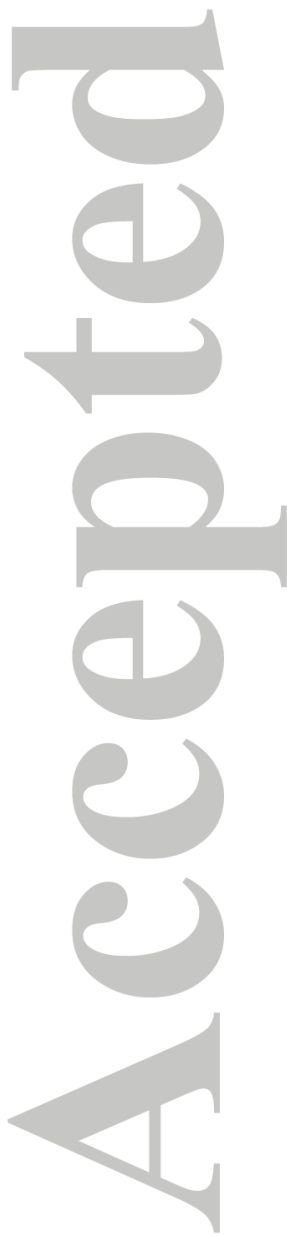

